\title{
Frequency of ABO-Rhesus Blood Groups in the Western Region of Saudi Arabia
}

\author{
Faisal M. Alzahrani, MSc, PhD, Saeed S. Shaikh, MD, \\ and Muzaheed A. Rasheed, MSc, PhD
}

Department of Clinical Laboratory Sciences, College of Applied Medical Sciences, Imam Abdulrahman Bin Faisal University, Dammam, Saudi Arabia

\section{Correspondence}

Dr. Saeed S. Shaikh

P. O. Box 76447

Al-Khobar 31952, Kingdom of Saudi Arabia

e.M: ssshaikh@iau.edu.sa

Submission: 23 Jan 2018

Accepted: 16 Feb 2018

\section{Citation}

Alzahrani FM, Shaikh SS, and Rasheed MA. Frequency of $\mathrm{ABO}$-rhesus blood groups in the western region of Saudi Arabia. JKAU Med Sci 2018; 25 (1): 9-13. DOI: 10.4197/Med. 25.1.2

\begin{abstract}
The western region of Saudi Arabia is known as a multinational region with different ethnic groups of people. This study aims to evaluate the $\mathrm{ABO}$ and rhesus blood groups among study subjects in the Western area of Saudi Arabia and their comparison with other regions of the Kingdom. It is a retrospective study. 35,388 participants were included. $\mathrm{ABO}$ blood grouping was done using tube method. Agglutination in any tube or hemolysis was considered as positive. Blood grouping was done by a preliminary finger prick, and was repeated again and a serum sample was obtained at the time of donation. Statistical Package for Social Sciences software was used for the data analysis. Results showed that the most common blood group is O, (50.1\%) followed by $A(29.7 \%), B(16 \%)$ and less frequent is $A B(4.1 \%)$. Rhesus positive were $91.3 \%$, while rhesus negative were $8.63 \%$. These results demonstrate that the most common blood group in the Western province is $\mathrm{O}$. Blood group A was noticed to be less frequent. Understanding the frequencies of the blood groups and their phenotypes is crucial for blood banking and for setting transfusion service protocols.
\end{abstract}

\section{Keywords}

ABO blood groups; Western region; Saudi Arabia

\section{Introduction}

Ko arl Landsteiner, an Austrian scientist had discovered the concept of $A B O$ blood grouping system in 1900 which was the major invention in the blood transfusion medicine history. He originated three diverse blood varieties and he labelled them as $A$, B, and O blood groups. In 1902, Alfred Von Decastello and Adrian Sturli revealed the $4^{\text {th }}$ variety $A B^{[1,2]}$. Basis of blood groups is grounded on genetical ingredients which are inborn over the outer layer of erythrocytes ${ }^{[3]}$. Therefore, these groups have been categorized into four varieties: $A, B, A B$ and $O$ in the $A B O$ system ${ }^{[4]}$.
Many research reports have defined occurrence of $A B O$ and rhesus $(\mathrm{Rh})$ phenotypes in diverse inhabitants of the world. Even though $A B O$ blood groups are determined at conception and continue during the course of life, deviating phenotypic consequences have been found through different ethnic residents in diverse environmental limitations ${ }^{[5,6]}$.

The worth of blood grouping system not only exist in laboratory medicine, their worth in people genome, residents journey designs, forensic medicine and doubtful parenthood cases is also well recognized ${ }^{[7,8]}$. Clinical implication of blood group systems rest on capability of agglutinins, which lead to the occurrence 
of hemolytic transfusion reactions and hemolytic disease of the fetus and newborn.

Occurrence of ABO blood groups differs geographically all over the world. Variety as well as inventory of blood and blood yields existing in the hospital transfusion medicine section in any community have to preferably carefully associate through the delivery of the clinically noteworthy erythrocyte antigens in the common populace ${ }^{[9]}$. The awareness of dissemination of $A B O$ blood grouping is vital for effective organization of blood bank portfolios at the provincial and countrywide stages ${ }^{[10]}$. Precise research studies have been passed out on the frequency of $A B O$ and Rh blood groups all over the kingdom.

Therefore, the theme of our research was to govern the incidence of $A B O$ and $\mathrm{Rh}$ systems in Saudi blood donors in King Abdulaziz Medical City of the National Guard, Jeddah, Western Region of Saudi Arabia.

\section{Materials and Methods}

This is a retrospective study to review and analyse blood donor's data from the last two years.

Any healthy subject eligible for blood giving for donation purposes and not for therapeutic purposes. 35,388 participants were included in our research from February 2014 to February 2016. Altogether ABO and Rh were serologically tested in the transfusion medicine section of King Abdulaziz Medical City of the National Guard, Jeddah. ABO blood grouping were conceded out via tube technique by means of market based primed antisera. Agglutination in any tube or hemolysis establishes affirmative outcomes. $\mathrm{ABO}$ blood grouping was conceded out via primary digit puncture, and were repeated over and a serum taster was acquired on the spell of contribution. IBM SPSS Statistics for Windows, Version 20 (IBM Corp., Armonk, NY USA) was used for data scrutiny. We did not consider any ethical approval because the study was retrospective and was based on patient's past laboratory test result record.

\section{Results}

In this study, an aggregate of 35,388 blood donors were screened for $A B O$ and $\mathrm{Rh}$ grouping. Results showed in Table 1 that the major blood group is $\mathrm{O}$, (50.1\%). The least frequent blood group is $A B(4.1 \%)$. Overall occurrence of $A B O$ blood groups during this study were the following: $50.1 \%$ Group O; $29.7 \%$ group
A; $16 \%$ group $B$ and $4.1 \%$ group $A B$ (Table 1). Incidence of $\mathrm{Rh}+$ and $\mathrm{Rh}$ - existed as: $\mathrm{Rh}+$ remained $91.3 \%$, while Rh- remained $8.63 \%$ (Table 2).

These results demonstrate that supreme common blood group in the Western province is $\mathrm{O}$. A was noticed to be less frequent relative to that observed in Western populations. Understanding the frequencies and

Table 1. Frequency occurrence of $A B O$ blood groups among blood donors.

\begin{tabular}{|c|c|}
\hline Blood Groups & Percentage (\%) \\
\hline 0 & $50.10 \%$ \\
\hline A & $29.70 \%$ \\
\hline B & $16.01 \%$ \\
\hline AB & $4.12 \%$ \\
\hline
\end{tabular}

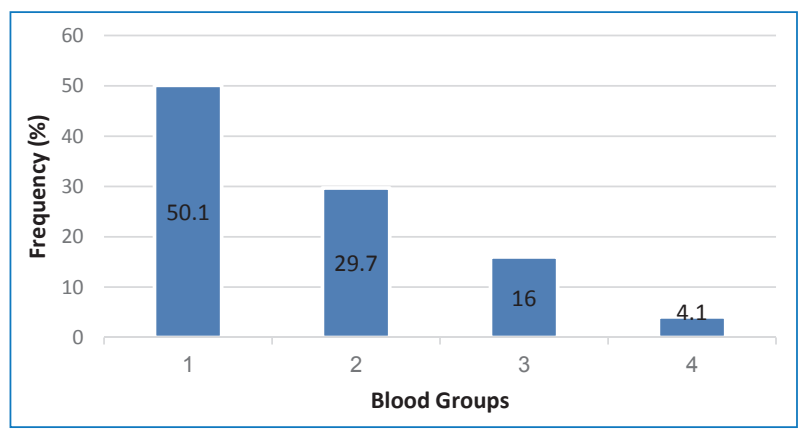

Table 2. Frequency occurrence of rhesus factor among blood donors.

\begin{tabular}{|c|c|}
\hline Rh Factor & Percentage \\
\hline Rh Positive & $91.31 \%$ \\
\hline Rh Negative & $8.63 \%$ \\
\hline Rh $=$ Rhesus
\end{tabular}

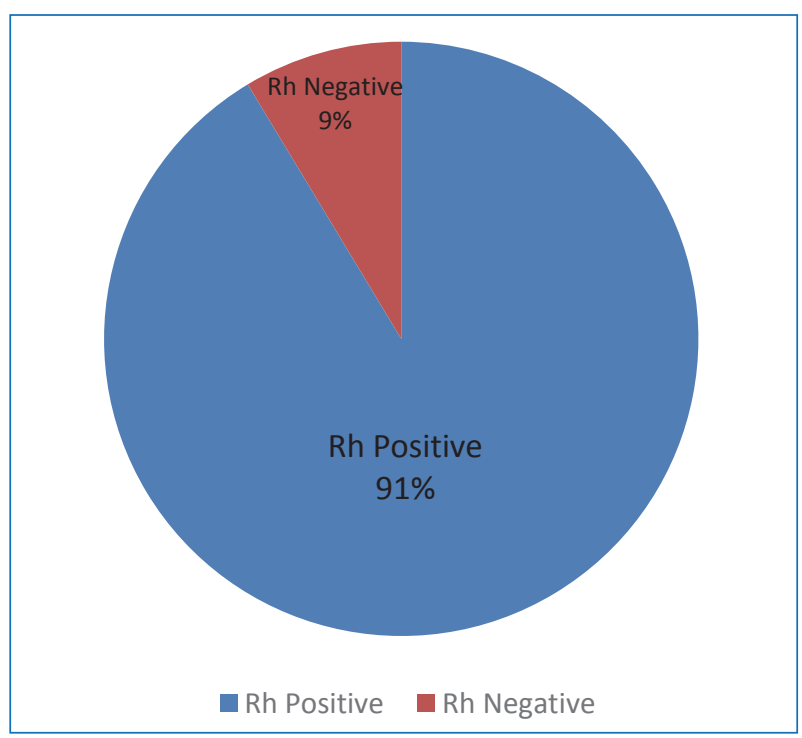


distribution of the blood groups and their phenotypes is crucial for blood banking and for setting transfusion service protocols. This is also imperative for scientific and population studies (e.g., disease association).

\section{Discussion}

Our research study revealed that the predominant blood group is $\mathrm{O}(50.1 \%)$ and the least frequent blood group is $A B(4.1 \%)$. Some studies already described the incidence and dissemination of $A B O$ as well as $\mathrm{Rh}$ systems in different parts of country. Mondal et al. ${ }^{[1]]}$ showed that incidence of $\mathrm{O}$ was recorded uppermost (36\%), tracked by B (33\%), A (22.5\%) and lowermost incidence remained observed with $A B(6.49 \%)$. Their outcomes stay very nearly to this research as well as to results reported by Hamed et al. ${ }^{[12]}$. All these studies including the present study display common occurrence of variety $\mathrm{O}$ and prove that this one isn't exclusive to any one area of the Kingdom. Keramati et al. ${ }^{[13]}$ described $A B O$ incidence over northern as well as eastern Iran in the direction of $O>A>B>A B$ whereas this one also remained same (direction) in Nojavan et al's. study ${ }^{[14]}$; both of these workings remained in similarity through the outcomes of our reasearch.

Our research study outcomes are also in accordance by means of the researches completed elsewhere in African countries ${ }^{[5,15]}$. Same dissemination of $A B O$ system has been grasped in researches piloted amongst Western Europeans, Bangaali populace, the African-American and Caucasian populace of United States ${ }^{[16]}$.

Research reported in United States, Mauritania, Kenya, Thailand, Saudi Arabia, Gaza, Nigeria, and Jordan, blood group " $O$ " was the predominant and $A B$ the less prevalent blood group ${ }^{[17]}$. Their findings are similar to that of our research study results.

The results of this study describe occurrence of blood groups from the Kingdom's Western region where a multi nationality with different ethnic groups of people of which some originally belong to the Arabian Peninsula while others originally belong to different parts of the world, especially Asia. Our outcomes might support in framing a nationwide total for upcoming orientation or database setting for the $\mathrm{ABO}$ and $\mathrm{Rh}$ frequency.

\section{Conclusion}

These results demonstrate $\mathrm{O}$ as the most common variety all over the Western province. A was noticed to be less frequent relative to that observed in Western populations. Understanding the frequencies and distribution of the blood groups and their phenotypes is crucial for blood banking and for setting transfusion service protocols. This is likewise significant for hospital based and population based researches (e.g., pathological relationship).

\section{Conflicts of Interest}

The authors declare that there are no conflicts of interest regarding the publication of this paper.

\section{Disclosure}

The authors of this publication had received research support from the Deanship of Scientific Research of the Imam Abdulrahman Bin Faisal University, Dammam. The terms of this arrangement have been reviewed and approved by the University in accordance with its policy on objectivity in research.

\section{Ethical Approval}

Not required.

\section{References}

[1] Eweidah MH, Rahiman S, Ali MH, Al-Shamary AM. Distribution of $\mathrm{ABO}$ and rhesus (RHD) blood groups in AlJouf province of the Saudi Arabia. Anthropologist 2011; 13(2): 99-102.

[2] Behra R, Joshi YR. Distribution of ABO blood group and RH (D) factor in Western Rajasthan. Natl J Med Res 2013; 3(1): 73-75.

[3] Kondam A, Chandrashekar M. A study of "incidence of hypertension in $\mathrm{ABO}$ and rhesus blood group system". Int J Biol Med Res 2012; 3(1): 1426-1429.

[4] Nishi K, Gupta NK, Sharma SC. Study on the incidence of hypertension and migraine in ABO blood groups. ISCA J Biological Sci 2012; 1(2): 12-16.

[5] Akinnuga AM, Bamidele O, Amosu AM, Ugwah GU. Distribution of $A B O$ and Rh Blood Groups among Major Ethnic Groups of Medical Students of Madonna University Teaching Hospital, Elele, Nigeria. Asian J Med Sci 2011;3(3): 106-109. 
[6] Chandra T and Gupta A. Association and distribution of hypertension, obesity and $\mathrm{ABO}$ blood groups in blood donors. Iran J Ped Hematol Oncol 2012; 2(4): 140-145.

[7] Pennap GR, Envoh E, Igbawua I. Frequency distribution of hemoglobin variants, $A B O$ and rhesus blood groups among students of African descent. Br Microbiol Res J 2011; 1(2): 33-40.

[8] Mondal B, Maiti S, Biswas BK, Ghosh D, Paul S. Prevalence of hemoglobinopathy, $\mathrm{ABO}$ and rhesus blood groups in rural areas of West Bengal, India. J Res Med Sci 2012; 17(8): 772776.

[9] Bhat YR, Kumar CG. Morbidity of ABO haemolytic disease in the newborn. Paediatr Int Child Health 2012; 32(2): 93-96.

[10] Hoffbrand AV, Moss PA. Essential Haematology. 6th edn. Hoffbrand AV, Moss PA, Pettit JE, eds. Chichester, UK: WileyBlackwell, 2011.

[11] Mondal B, Maiti S, Biswas BK, Ghosh D, Paul S. Prevalence of hemoglobinopathy, $\mathrm{ABO}$ and rhesus blood groups in rural areas of West Bengal, India. J Res Med Sci 2012; 17(8): 772776.

[12] Hamed CT, Bollahi MA, Abdelhamid I, Med Mahmoud MA, Ba B, Ghaber S, Habti N, Houmeida A. Frequencies and ethnic distribution of $A B O$ and $R h(D)$ blood groups in Mauritania: results of first nationwide study. Int J Immunogenet 2012; 39(2): 151-154.

[13] Keramati MR, Shakibaei $H$, Kheiyyami Ml, Ayatollahi $H$, Badiei Z, Samavati M, Sadeqhian MH. Blood group antigens frequencies in the northeast of Iran. Transfus Apher Sci 2011; 45(2): 133-136.

[14] Nojavan M, Shamsasenjan K, Movassaghpour AA, Akbarzadehlaleh P, Torabi SE, Ghojazadeh M. Allelic prevalence of $\mathrm{ABO}$ blood group genes in Iranian Azari population. Bioimpacts 2012; 2(4): 207-212.

[15] Mbalibulha Y, Muwanguzi E, Mugyenyi GR, Natukunda B. Occurrence of anti-D alloantibodies among pregnant women in Kasese District, Western Uganda. J Blood Med 2015; 6: 125-129.

[16] Talukder SI, Das RK. Distribution of $A B O$ and Rh blood groups among blood donors of Dinajpur district of Bangladesh. Dinajpur Med Col J 2010; 3(2): 55-58.

[17] Giri PA, Yadav S, Parhar GS, Phalke DB. Frequency of ABO and rhesus blood groups: A study from a rural tertiary care teaching hospital in India. Int J Biol Med Res 2011; 2(4): 988-990. 


\title{
معدل تكرر فصائل الدم ( ABO-Rh ) في المنطقة الغربية من الملككة العربية

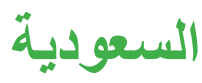

\author{
فيصل الزهراني، وسعيد ستار شيخ، ومجاهد عبدالرشيد \\ قسم علوم المختبر/ت الإكلينبكية التئية \\ كلبة العلوم الطبية التطبيقية

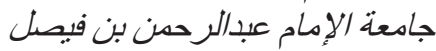 \\ الدمام ـ المعلكة العربية السعودية بدام فية
}

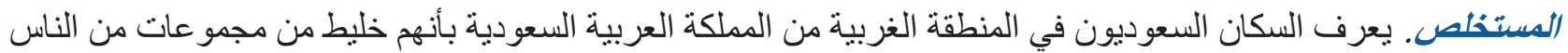

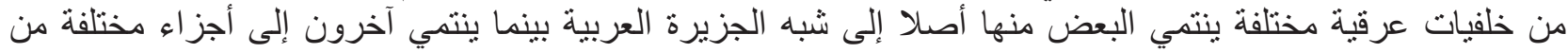

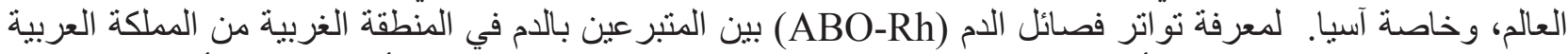

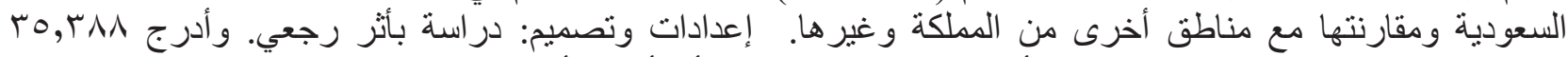

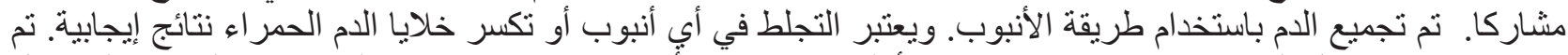

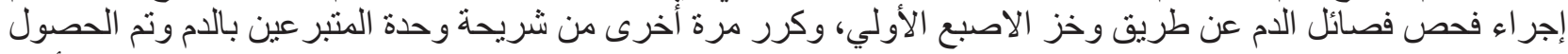

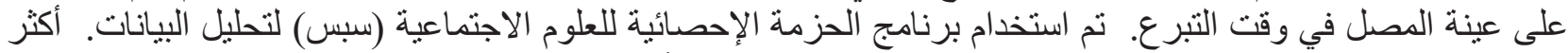

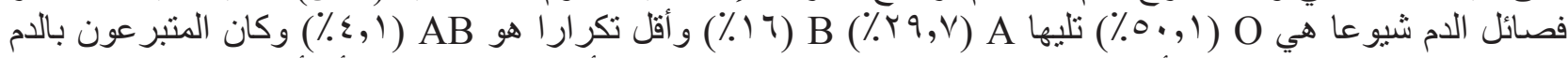

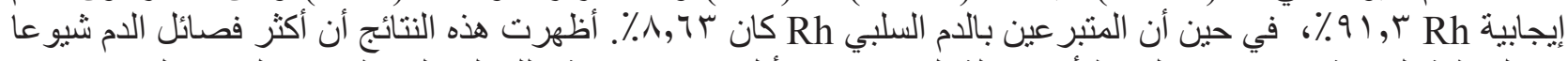

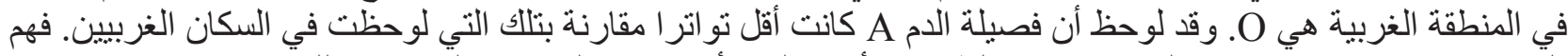

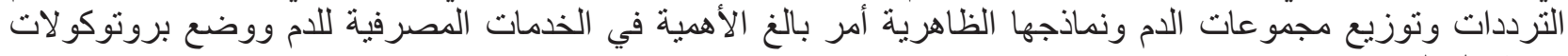
خدمة نقل الدم. 